\title{
DUALITY NATURE OF SELECIIVE ANDROGEN RECEPTOR MODULATORS AND SPECIFIC STEROIDS SUBSTANCE
}

\author{
Damian Gorczyca' ${ }^{1}$, Dorota Kwiatkowska² ${ }^{\circledR}$ \\ 1 Lazarski University, Warsaw, Poland \\ ${ }^{2}$ The Polish Anti-Doping Laboratory, Warsaw, Poland
}

\section{ABSTRACT}

Selective Androgen Receptor Modulators (SARMs) are the novel class of the androgen receptors (AR), often called tissue-selective AR ligands. Discovery of SARMs will give a possibility to the alternative therapy for androgens therapy (osteoporosis, prostate cancer, muscle wasting). SARMs should have high specificity for the AR, tissue-selective pharmacokinetic activities, improved oral bioavailability and pharmacokinetic profile which allows once-a-day administration [1].

Example of SARMs is flutamide (flutamidum, Eulexin, imid 2-methyl-N-\{4-nitro-(3-trifluoromethyl)-phenyl]-propionic acid), a synthetic nonsteroidal drug that is a competitive antagonist of the androgen receptor. SARMs were recognized as forbidden substances by the World Anti-Doping Agency (WADA) and since 2004 they are on the Prohibited List. To point on the Prohibited List 2019 "Substance and methods prohibited at all time (in- and out-of-competition)" SARMs belong to group S1. 2. Other Anabolic Agents, and to group S4. Hormone Antagonist and Modulators [2].

The main role of an anti-doping laboratory is to analyse and to determine whether a given substance should be prohibited in sport. The principal analyses of SARMs and Specific Steroid Substance are a different variant of chromatography (LC - liquid or GC - gas) with many detection techniques (MS - mainly mass spectrometer, MS/MS - tandem mass spectrometer).

KEY WORDS: SARMs, SERMs, antiandrogens, antioestrogens, doping analysis

Disaster Emerg Med J 2019; 4(2): 60-62

\section{INTRODUCTION}

\section{Clinical applications of SARMs}

SARMs can be divided into two different classes compounds: nonsteroidal and steroidal antiandrogens (Tab. 1). The major goal in the development of SARMs is to prevent the undesirable side-effects of treatment by improving the tissue selectivity of the ligands. This would greatly enlarge the clinical applications of these ligands beyond primary and secondary hypogonadism. Other applications of SARMs include hormone-replacement therapy, os-
Table 1. Pharmacological differences between steroidal and nonsteroidal antiandrogens

\begin{tabular}{|l|l|}
\hline \multicolumn{1}{|c|}{ Steroidal antiandrogens } & Non-steroidal antiandrogens \\
\hline Block androgen binding to & Block androgen binding to \\
its specific receptor & its specific receptor \\
Have progestational & Do not have progestational \\
properties & properties \\
Suppress gonadotropin & Do not suppress \\
Serum luteinising hormone & gonadotropin \\
levels are decreased & Serum luteinising hormone \\
Testicular testosterone & levels are not reduced \\
synthesis is reduced & Testicular testosterone \\
& synthesis is not reduced \\
\hline
\end{tabular}


teoporosis, muscle wasting, male contraception and prostate cancer. The dual effects of SARMs in muscle and bone might be particularly advantageous for the treatment of osteoporosis because an increase in muscle mass and strength might help rebuild bone mass and also reduce the risk of fracture because of a reduced chance of fall [1].

The biggest advantage of anabolic SARMs is that these ligands might be safe to use in women therapy. Improving tissue selectivity, SARMs that keep steady the anabolic actions of androgens without causing the virilizing effects associated with traditional androgen therapies, open the door to potential applications in hormone-replacement therapy (HRT) in postmenopausal women, osteoporosis or sexual functions.

Flutamide (amid 2-methyl-N-[-4-nitro-(3-trifluoromethyl)-phenyl]-propionic acid; Fig 1.) is one of the compound rates to nonsteroidal antiandrogens. It's easily absorbed from the digestive system, and it's mainly metabolised to hydroxyl derivative. Primarily used to treat prostate cancer. Minority clinical effect has cyproterone acetate (steroidal antiandrogen). It is a derivative of synthetic progesterone drug with very strong androgen action, curbed androgen production in the renal cortex and blocked testosterone binding receptors.

\section{DISCUSSION}

Specific Steroids Substance are a class of compounds named antioestrogens. Antioestrogens can be divided into two different groups: selective antioestrogen receptor modulators (SERMs) and aromatase inhibitors. In 1958, Lerner and co-workers published their landmark paper on the pharmacological properties of the first nonsteroidal antioestrogen ethamoxytriphetol or MER-25. Lerner later wrote, "the compound was appealing not only because it completely inhibited the uterine response to oestradiol $\left(E_{2}\right)^{b}$ but also because it was devoid of uterine stimulatory properties. Antioestrogens are a class of medication that acts on the oestrogen receptor compounds in cytoplasmic cells, especially sensitive for oestrogens (teat cells, womb cells, hypothalamus, pituitary gland) [3].

Tamoxifen, a first-generation selective oestrogen receptor modulator, was introduced as a treatment option for breast cancer more than three decades ago. It is now used among women of all ages for the treatment of breast cancer, irrespective of cancer<smiles>CC(=O)Oc1ccc(C(=C2CCCCC2)c2ccc(OC(C)=O)cc2)cc1</smiles>

Cyclofenil (Hydroxy-bis-desacetyl-cyclofenil)<smiles>C=C1CC2C(CCC3(C)C(=O)CCC23)C2(O)C=CC(=O)C=C12</smiles>

Exemestane<smiles>CC(C)C(=O)Nc1ccc([N+](=O)[O-])c(C(F)(F)F)c1</smiles>

Flutamide (Eulexin ${ }^{\text {TM }}$ )

FIGURE 1. Chemical structure of anti-androgens

stage. Tamoxifen is also approved by the U.S. Food and Drug Administration as a chemo preventive agent against breast cancer and is now prescribed to women at high risk of this disease. However, the drug has serious side effects, like endometrial cancer and venous thrombotic events which may be dose-dependent or related to the accumulated dose [4].

Antiandrogens and antioestrogens have gained universal recognition as prohibited substances. by WADA.

In the year 2019 they are classified as:

Group S1. 2. Other Anabolic Agents, including but not limited to:

Clenbuterol, selective androgen receptor modulators (SARMs), tibolone, zeranol, zilpaterol and Group S4.vHormone Antagonists and modulators 
The following classes are prohibited:

1) Aromatase inhibitors including, but not limited to: anastrozole, letrozole, aminoglutethimide, exemestane, formestane, testolactone.

2) Selective oestrogen receptor modulators (SERMs) including, but not limited to: raloxifene, tamoxifen, toremifene.

3) Other antiestrogenic substances including, but not limited to: clomiphene, cyclofenil, fulvestrant.

4) Agents modifying myostatin function(s) including but not limited to: myostatin inhibitors.

Antiandrogens and antioestrogens are popular in sports circle for a few years. They are very popular in male sports. In doping world antiandrogenic substances are called as mask substance by the influence of the decrease of androgens, thereby changing concentration of steroid profile.antiestrogens, however, such as tamoxifen or clomiphene, have stimulating effects on the secretion of hypophysic gonadotropic hormones. They are mainly used in the treatment of infertility. In males, antiestrogenic substances may cause an increase of the endogenous production of androgens. Athletes may be encouraged to treat the adverse effects of extensive abuse of anabolic androgenic steroids (e.g. suppression of androgens, gynecomastia) by using antiestrogenic drugs [5]. WADA is publishing the statistic of the prohibited substances Identified in Each Drug Class (Tab. 2) [6].

\section{CONCLUSIONS}

To analyse Selective Androgen Receptor Modulators and other Specific Steroids Substance all WADA
Table 2. Substances Identified as AAFs* in Each Drug Class in ADAMS (All Sports) [6]

\begin{tabular}{|l|l|l|}
\hline $\begin{array}{c}\text { S.4 Hormone and } \\
\text { Metabolic Modulators }\end{array}$ & Occurrences & $\begin{array}{c}\% \text { within the drug } \\
\text { class }\end{array}$ \\
\hline Clomifene & 65 & $20 \%$ \\
Tamoxifene & 64 & $20 \%$ \\
Anastrozol & 40 & $12 \%$ \\
Letrozol & 22 & $7 \%$ \\
6-OxO-androstenedione & 1 & $0.3 \%$ \\
Raloxifene & 1 & $0.3 \%$ \\
\hline * The Adverse Analytical Findings (AAFs) in these tables are not to be confused with \\
adjudicated or sanctioned Anti-Doping Rule Violations (ADRVs), as the figures given \\
in this report may contain findings that underwent the Therapeutic Use Exemption \\
(TUE) approval process or multiple findings on the same Athlete \\
\hline
\end{tabular}

accredited laboratories are using all selective and sensitive methods, like liquid and gas chromatography with selective detectors and mass spectrometers. The key to a high stand of art in anti-doping analysis is to detect all parents compounds and also all metabolites. All classes of these compounds are on the Prohibited List [2].

\section{REFERENCES}

1. Wenqing G, Dalton JT. Drug Discovery Today. 2007; 12: 241 .

2. World Anti-Doping Agency: The 2019 prohibited list, World Anti-Doping Agency, Montreal (2019). http://www.wada-ama.org/rtecontent/ document/2019_List_En.pdf (14.07.2019).

3. Macgregor Jl, Jordana C. Pharmacological Reviews. 1998; 50: 151.

4. Gjerde J, et al. Chromatogr A. 2005; 1082: 6 .

5. Thevis M., Kamber M., Schänzer W. Proceeding of the 5th Workshop on Dope analysis. Cologne, 2000.

6. World Anti-Doping Agency: WADA annually publishes statistical reports as reported by the WADA-accredited laboratories in ADAMS, 2017 Anti-Doping Testing Figures Report - Executive Summary (online 14.07.2019). 